\title{
THE SCOPE OF THE CONSTRUCTION OF EXPERIENCE IN EMPIRICIST STRUCTURALISM
}

\author{
NÉLiDA GENTILE
}

\begin{abstract}
In his attempt to put forward an empiricist version of structuralism, van Fraassen develops an approach to scientific representation and models which has been the object of several critiques. Here we cover the "Loss of Reality Objection", namely, that reality itself would play no role in science if science could only refer to mathematical models. We examine and dismiss the solution offered by van Fraassen. Finally, we offer an alternative solution path.
\end{abstract}

Keywords: Constructivism; reality; empiricist structuralism; empirical models.

\section{Introduction}

In the paper "Structure: Its Shadow and Substance", published in 2006, van Fraassen lays the foundations for his new empiricism, empiricist structuralism. In the 1980s, in The Scientific Image, he had presented constructive empiricism as an alternative to traditional scientific realism. In opposition to the idea that "Science aims to give us, in its theories, a literally true story of what the world is like; and acceptance of a scientific theory involves the belief that it is true" (van Fraassen 1980, p.8), he formulates his anti-realist proposal arguing that "Science aims to give us theories which are empirically adequate; and acceptance of a theory involves as belief only that it is empirically adequate" (van Fraassen 1980, p.12). A quarter of a century later he makes a turn towards structuralism. Although the idea of structure was somewhat already present in The Scientific Image, it now acquires a fundamental role that leads to new approaches in his image of science. He then presents empiricist structuralism as an alternative to the structural realism originally formulated by Worrall in "Structural Realism: The Best of Both Worlds?" (1989). ${ }^{1}$

Worrall presented structural realism as a version of realism that seeks to reconcile some aspects derived from the no-miracle argument-the idea that there is something that is conserved through theory changes and that accounts for predictive successwith certain intuitions based on the history of science regarding a radical discontinuity. His strategy consists in establishing a distinction between the content and the mathematical structure of a theory, so that in the passage from one theory to another there may be a substantial change in content, an abrupt alteration of the referential continuity, together with the permanence of the mathematical equations. The theories of Fresnel and Maxwell, to take Worrall's example, conceived of light differently:

Principia 21(3): 445-459 (2017).

Published by NEL — Epistemology and Logic Research Group, Federal University of Santa Catarina (UFSC), Brazil. 
in one case light was a periodic disturbance originating in a source and transmitted through a mechanical medium: ether; in the other, it was a periodic disturbance within an electromagnetic field. Obviously, the nature of light was understood differently and the theoretical mechanisms postulated by Fresnel were not incorporated in Maxwell's hypotheses. However, according to Worrall, there is a structural continuity: the mathematical equations of the old theory are kept in the successor theory as limiting cases.

More recently, structural realism was developed in two versions: epistemic structural realism and ontic structural realism. The former maintains that the only thing we can know about noumenal reality are the structural relationships between the facts but not the entities or their properties - this is the variety defended, in addition to Worrall, by Weyl (1963) and Zahar (1996). Ontic structural realism, on the other hand, is characterized by maintaining a much stronger thesis: that we can only know the structure of the universe because it is the only thing there is (Ladyman 1998, French 1999). It is not the aim of this work to delve into the theses of structural realism. Rather, we are interested in van Fraassen's reaction to this position, which led him to formulate his alternative proposal, empiricist structuralism.

Van Fraassen characterizes Worrall's structural realism by identifying three theses: i) scientific knowledge is, in some sense, cumulative; ii) this cumulative knowledge refers to aspects of the world that go beyond the observable reality; and iii) what we come to know is only the structure of reality, and not what reality is in itself. He adds that Worrall's way to base these affirmations introduces certain unrecognized remnants of metaphysical components. For structural realism assumes an objective and contextually — independent distinction between mere qualities and the relational structure in which these qualities are presented, and this intrinsic / extrinsic distinction can only be maintained at the expense of venturing into the field of metaphysics (van Fraassen 2006, p.297). Thus, van Fraassen judges that the idea that science exhibits an accumulation of knowledge is legitimate, but consistently with his empiricist spirit, he considers that this accumulation occurs strictly at the empirical level, the level of phenomena: it is the surface structure of science, the phenomenal structure, which is stable, in contrast with its theoretical content, which is rapidly altered (van Fraassen 2006, p.304). In other words, the success of old theories resided in that the models proposed for the representation of observed phenomena were partially correct to account for the data of observational and experimental experience, to accommodate the structure of the phenomena (van Fraassen 2006, p.303). And it is this phenomenal structure, defined by certain measurable parameters, what remains stable-within a certain level of approximation - and is used by both the old and the new theory to describe empirical success (van Fraassen 2006, pp.303-304). But the story does not end here. In his attempt to develop an empiricist version of structuralism, in Scientific Representation: Paradoxes of Perspective (2008) and "The

Principia 21(3): 445-459 (2017). 
Criterion of Empirical Grounding in the Sciences" (2012), van Fraassen deepens certain points already presented in his 2006 paper and develops an approach to scientific representation and models.

In this paper we examine the Objection to the Loss of Reality, which is one of the main objections generated against van Fraassen's theory of representation, and we propose a possible solution to it. After describing the most salient features of van Fraassen's approach to representation (section 2), we will present the above - mentioned objection - which was advanced by van Fraassen himself- and analyze the solution he proposed (section 3). Next, we point out certain problematic aspects undermining the viability of his proposal (section 4), and, finally, we offer an alternative solution path (section 5).

\section{Representation and Models}

According to van Fraassen, structuralism finds its own articulation only in an empiricist framework and can be summarized in the following two theses (van Fraassen 2008, p.238):

I. Science represents the empirical phenomena as embeddable in certain abstract structures (theoretical models).

II. Those abstract structures are describable only up to structural isomorphism.

Van Fraassen's approach to representation delineates a first distinction between phenomena (observable objects, events or processes of any kind) and appearances (the content of measurement results) (van Fraassen 2008, p.283) ${ }^{2}$ According to van Fraassen, the distinction between phenomenon and appearance corresponds, for example, to the difference between Mount Everest, on the one hand, and the different perspectives that can be had of Mount Everest from different directions, on the other. The same can be applied to planetary orbits and their appearances for a terrestrial observer. A phenomenon can be measured and observed in very different ways, and the way it will appear in the measurement results will vary from one way of measuring and observing to another, since these results provide only perspectives of phenomena. But van Fraassen makes it clear that the way in which an observable object or process (phenomenon) appears in the results of measurements (appearances) is in itself an intersubjectively accessible, public and objective fact.

At the level of appearances, in turn, van Fraassen makes a distinction between the "data model" and the "surface model". The data model is constructed from the raw data collected at different moments of the research, for example, a graph of temperature that summarizes the different measurements of temperature collected in various parts of a region at different times of the day. The surface model, on the

Principia 21(3): 445-459 (2017). 
other hand, is an idealization of the already available information to replace it with more sophisticated information; it substitutes, for example, relative frequencies for a continuous range of values.

In addition to phenomena and appearances, there are theoretical models, which, strictly speaking, are the vehicles of scientific representation. As we have pointed out, the central thesis of empiricist structuralism holds that science represents empirical phenomena as embeddable in certain abstract structures (theoretical models). In short, science tends to give representations of nature, and scientific representation includes three domains (van Fraassen 2008, p.289):

[1 ] Theoretically postulated reality — Micro structure, forces, fields, global spacetime structures

[2 ] The observable phenomena - Macro objects, motions, tangible and visible bodies, ...

[3 ] The appearances - Measurement outcomes, "how things look" in observational context.

We will return later to the notions of phenomenon and appearance. For the time being, this brief description of van Fraassen's representational approach is sufficient to understand one of the main objections to which it gave rise, namely, the Loss of Reality Objection.

\section{The Loss of Reality Objection and the Pragmatic Tautology}

Given the conjunction of theses i) and ii), that is, that science represents the empirical phenomenon as "embedded" in certain abstract structures, on the one hand, and that abstract structures are described only by isomorphism, on the other, a question immediately arises: How can an abstract structure represent phenomena, that is, entities of a physical nature? The problem is not new and has been pointed out by several authors (Rosenhagen 2006; Barrett 2009; Turn 2009; Nguyen 2016; Ghins 2016). Van Fraassen, of course, is aware of it and expresses the difficulty in the following terms: How can an abstract entity, such as a mathematical structure, represent something that is not abstract, that is, something that is found in nature? (van Fraassen 2008, p.239). Echoing the problem, he presents the objection in the following terms:

Oh, so you say that the only 'matching' is between data models and theoretical models. Hence the theory does not confront the observable phenomena, those things, events, and processes out there, but only certain representations of them. Empirical adequacy is not adequacy to the phenomena pure and simple, but to the phenomena as described! (van Fraassen 2008, p.258).

Principia 21(3): 445-459 (2017). 
And by virtue of considering that an empiricist approach to the sciences must respond to this objection, he then proposes: "Let us therefore honor it with a special name: the Loss of Reality Objection" (van Fraassen 2008, p.258). Indeed, if the target of the representation are the data models-the appearances and not the phenomena-then van Fraassen's position seems problematic: what we have is an isomorphic correlation between abstract structures without any anchoring in the real world.

We can ask why van Fraassen, self-identifying as an anti-realist, shows marked concern about the loss of reality. The answer lies, in our opinion, in the presuppositions of the particular kind of empiricism that he defends, whether it be constructive empiricism or the later position he embraced, empiricist structuralism. In both there is an underlying ontological-epistemic thesis: the distinction between observable entities, on the one hand, and unobservable entities (or abstract entities in the case of models), on the other hand. This distinction leads him to embrace a partially realist and partially agnostic position. Realist because observable objects exist independently of the subject. And agnostic because with respect to unobservable entities he suspends all kinds of ontological commitment that would immerse him in metaphysics. In other words, van Fraassen always assumed a realist position about the observable world, i.e. the phenomenal world. And this will have important consequences for the evaluation of van Fraassen's solution to the problem of the loss of reality, as we will see in the following sections.

Let's see then how van Fraassen responds to the objection, which we can put forward in the form of the following question: How is it possible that theories (theoretical models) represent phenomena if the matching is a relation between purely abstract structures (theoretical models, on the one hand, and data models, on the other hand)? The answer should be that the phenomena are represented by the data models. But it could be argued that this answer reiterates the problem, because the data models are themselves abstract structures while the phenomena are not abstract entities. Van Fraassen's answer is a kind of pragmatic identification of the data models with the phenomena. Such identification is supported by the fact that we are the ones who select certain aspects of the phenomena in order to build data models, and therefore, according to van Fraassen, it could be a pragmatic contradiction to reject such identification. The "construction of a data model is precisely the selective relevant depiction of the phenomena by the user of the theory required for the possibility of representation of the phenomenon" (van Fraassen 2008, p.253). The representation relationship is not a dyadic relationship between the model and the phenomenon, but it is a triadic relationship (between the model and the phenomenon as it is constituted by the user). Thus, he affirms that "Nothing represents anything except in the sense of being used or taken to do that job or play that role for us" (van Fraassen 2008, p.253), and adds: "Nor does the phenomenon [... ], taken by itself, determine 
which structures are data models for it. That depends on our selective attention to the phenomenon, and our decisions in attending to certain aspects, to represent them in certain ways and to a certain extent" (van Fraassen 2008, p.258).

Van Fraassen's response to recover the world is described by himself as a Wittgensteinian movement and it is illustrated through the following example: Suppose that somebody shows a graph where he intends to represent the growth of the population of deer in Princeton. According to a possible objection the graph about the growth of the deer population is something different from the actual growth of the deer population, which is a physical process in the world. However, van Fraassen states:

Since this is my representation of the deer population growth, there is for me no difference between the question whether $T$ fits the graph and the question whether $T$ fits the deer population growth (van Fraassen 2008, p.256).

And he adds that to deny such a thing would be tantamount to sustaining a contradiction of the form:

The deer population growth in Princeton is thus or so, but the sentence "The deer population growth in Princeton is thus or so" is not true, for all I know or believe (van Fraassen 2008, p.256).

It would be inconsistent that somebody presents the graph as representing something and at the same time he claims that perhaps it does not represent it. Thus, van Fraassen concludes that in the context of use there is no difference between the statement that (A) the theory is adequate to phenomena, and the statement that (B) the theory is adequate to the phenomena as represented by us: "That (A) and (B) are the same for us is a pragmatic tautology" (van Fraassen 2008, p.259), that is, a logically contingent but undeniable statement. Thus, van Fraassen's answer evades the Loss of Reality Objection by resorting to the pragmatic equivalence between the data models and the phenomena.

\section{Phenomena and appearances again}

We have seen that, according to van Fraassen, scientific representation includes three domains: theoretically postulated reality, the observable phenomena and the appearances. Let us now focus more closely on phenomena and appearances. Since The Scientific Image van Fraassen described phenomena as the observable things and events in the world. Recall the statement that "a theory is empirically adequate exactly if what it says about the observable things and events in this world, is true - exactly if it saves the phenomena" (van Fraassen 1980, p.12). The idea of saving the phenomena implies, then, to subscribe the distinction between observable and unobservable entities (different from the theoretical-observational dichotomy, which he conceives

Principia 21(3): 445-459 (2017). 
as a category mistake). ${ }^{3}$ But how does van Fraassen define "observable"? At least in The Scientific Image, he does not offer a clear elucidation of this notion. In response to Maxwell's criticisms about the impossibility of drawing the distinction between what is observable and what is not, van Fraassen provides a general characterization and explicitly states that "this is not meant as a definition, but only as a rough guide to the avoidance of fallacies" (van Fraassen 1980, p.16): "X is observable if there are circumstances which are such that, if $\mathrm{X}$ is present to us under those circumstances, then we observe it" (van Fraassen 1980, p.16). Such a characterization, even admitting that it is only a guide, still contains a certain circularity, due to the fact that the concept of observation is used to characterize what is observable. But leaving aside this circularity we should note that observability does not depend on us using an instrument but on the characteristics of the observed. Thus, van Fraassen maintains: "A look through a telescope at the moons of Jupiter seems to me a clear case of observation, since astronauts will no doubt be able to see them as well from close up" (van Fraassen 1980, p.16). He distinguishes this case from the detection of microparticles in a cloud chamber. While in the case of the cloud chamber there is also some observation, the entities detected, the microparticles, are unobservable because a human being like us could not observe them under any circumstances.

Phenomena, then, are the things and events that under certain circumstances would be observed. The fact that we have knowledge from their appearances does not mean that the phenomenon is not observable. Thus, van Fraassen says:

That mountain is undoubtedly an observable object — only weird philosophical jargon could decide differently - though of course we infer its shape from what its appearances are in telemetry data and photographs taken from various positions $[\ldots]$ and only a strange departure from common sense would lead us to the idea that e.g. mountains are only theoretically postulated entities (van Fraassen 2008, p.285).

In the same way, according to van Fraassen, planetary orbits are observable phenomena: "The planetary orbits differ from the mountain only in that measurements over time are needed, while in the case of a mountain a number of simultaneous measurements would do as well" (van Fraassen 2008, p.285).

As for appearances, van Fraassen recognizes that the expression "to save the phenomena" is often taken as meaning "to save the appearances". But, as we have pointed out, van Fraassen's appearances are "the contents of (possible) measurement outcomes" (van Fraassen 2008, p.284), e.g. the different perspectives of Mount Everest according to different points of view, or the varied movements of the planetary orbits observed and recorded from Earth, from a satellite or from outer space. Note, however, that in his argumentation van Fraassen alludes to appearances in a different sense. When referring to the Copernican system to illustrate the notion of appearance, he indicates:

Principia 21(3): 445-459 (2017). 
Specifically, the planetary 'retrograde' motions are, according to Copernicus, (mere) appearances. Mercury's retrograde motion is a good example of an appearance. Literally speaking this is something that does not happen - it does not exist! Mercury never turns back to reverse its orbital direction. But that is how it appears to the observer or the film camera, viewing from Earth. Mercury's motion is an observable phenomenon, but Mercury's retrograde motion is an appearance (van Fraassen 2008, p.287).

Clearly, the first three sentences allude to the retrograde movement as an appearance in the sense in which Copernicus used the term, as a non-real movement (perhaps this is why van Fraassen calls it a "mere" appearance). However, in the sentence that follows: "But that is how it appears to the observer or the film camera, viewing from Earth" it is not clear whether van Fraassen maintains the same sense or is speaking of appearances according to his own characterization. The same ambiguity is maintained at the end of the paragraph when he expresses: "What the Copernican does in order to credential his representation is, in effect, to explain by means of geometric optics and projective geometry how the visual appearances (content of outcomes of measurements made by astronomers) are produced from reality" (van Fraassen 2008, p.288). Note that van Fraassen says that Copernicus explains the vision of a retrograde movement using his own hypotheses about the real movements of the planets. The distinction between real movements and appearances underlying Copernicus' thought does not correspond to the distinction between phenomenon and appearance that emerges from the definitions introduced by van Fraassen. Although, of course, van Fraassen can reinterpret Copernicus' texts according to van Fraassen's definitions.

But leaving aside this ambiguity, we are interested in emphasizing another aspect related to appearances. Van Fraassen warns that planetary movements (and we could say Mount Everest) cannot be identified with their respective appearances. Thus he indicates:

Copernicus described the planetary motions. These motions are observable; they can be observed and also be registered on film, whether from Earth or from a satellite or from outer space. Copernicus depicted them clearly in a geometric model. They certainly cannot be identified with the appearance recorded by any such specific means as views through a telescope, successive photos over a period of many days, film, or video recording. The recording is always from a specific vantage point, and that point is arbitrary, it has no privileged status either in nature or in Copernicus's model. What is the content of such a recording then? It is the appearance of the planetary motions, for a photo, film, painting, or drawing displays how the recorded object, event, or process 'looks' from the chosen vantage point (van Fraassen 2008, p.287).

But remember that the solution proposed by van Fraassen to the Loss of Reality

Principia 21(3): 445-459 (2017). 
Objection rests, precisely, on a pragmatic identification of phenomena with data models, with their appearances. Does not it go against the internal coherence of empiricist structuralism? From a strictly logical point of view, it does not, because the rejection and acceptance of such identification are expressed at different levels: from a conceptual point of view van Fraassen rejects this identification, but at the pragmatic level he promotes it. Hence, the statements "The theory is adequate to phenomena" and "The theory is adequate to the phenomena as represented by us" are pragmatically equivalent for van Fraassen. However, van Fraassen's argumentation presents some weak flanks that, we believe, make it unconvincing. His solution to the problem of the loss of reality is based on a conceptual framework of interrelated notions mounted on the notion of observable: the strategy of pragmatic tautology is based on the distinction between phenomena and appearances, and the notion of phenomena, in turn, rests on the notion of observable. But, in our judgment, van Fraassen's discourse about these notions is misleading.

Indeed, regarding observability, we have seen that van Fraassen relies on the point of view of the common use about, for example, the observability of a mountain blaming weird philosophical jargon for any doubt that the mountain itself is observable. He also considers that with respect to their observability, there is no difference between mountains and planetary orbits. This is a curious analogy! Strictly speaking, it seems very far from common sense to claim that growth rates of deer populations or real planetary orbits are observable phenomena. Van Fraassen seems to restrict the unobservable only to the microphysical, those parts of the world of which we do not even have appearances and on which he adopts an agnostic attitude. However, we believe that there is a very large leap between the example of the mountain and that of the rate of growth of deer, and another leap even greater between the latter and the example of planetary movements. With respect to the mountain, the different appearances are enough to believe in the existence of the object, but this is more debatable in the case of the growth of deer, and much more doubtful in the case of planetary orbits. If orbits are observable, it is difficult to understand why, faced with the same appearances, Ptolemaic and Copernican astronomers debated for more than a century what the planetary movements were.

On the other hand, to the extent that appearances are multiple while the phenomenon is only one, it is illegitimate to identify (albeit pragmatically) the appearances with the phenomena. Identifying the one with the multiple results in an extreme rhetorical license, an ad hoc tactic.

Given the above-mentioned complications, van Fraassen does not seem to satisfactorily answer the Loss of Reality Objection. We can, however, try a possible solution path that is perfectly compatible with the spirit of empiricist structuralism.

Principia 21(3): 445-459 (2017). 


\section{The Permanence of the World (or Empiricism with a Human Face)}

Recall that van Fraassen himself has explicitly stated that he only very slowly recognized the importance of introducing a distinction between phenomena and appearances, a distinction that was absent in The Scientific Image. Within the framework of his new position, empiricist structuralism, the role that data models play in the representation of phenomena is decidedly more important, we could say that it is central. We could also say that with respect to knowledge of the phenomenal world, van Fraassen maintains an indirect realist attitude. But a difference could be established between common sense phenomena and phenomena linked to scientific knowledge. While in common sense knowledge we have appearances that are visual images originated from different points of view, in knowledge linked to science we need systematic observations, measurements, experiments, construction of data models, surface models, etc., so that such phenomena seem much more mediated than ordinary phenomena. Thus, the realist attitude that van Fraassen always maintained regarding the phenomenal world seems to approach the type of indirect realism or representative realism featured in the doctrine of Locke.

According to indirect realism, we do not directly perceive the objects of the external world, the mind instead knows through certain intermediaries, variously described in different versions of indirect realism as "sense data", "ideas", "sensibilia", "percepts", or "appearances". Thus, Locke states, "It is evident the mind knows not things immediately, but only by the intervention of the ideas it has of them" (Locke, 1690, Book IV, Chapter IV, §3). Sense data are, therefore, intermediaries between the agent that perceives and the external world, and it is from them that we make inferences to form empirical beliefs that help us to represent the external world to ourselves in the most accurate way possible.

Since we can have direct knowledge only of our sense data, skepticism seems to be the natural consequence: all of our beliefs about the external world might be false, physical objects are nothing more than sense data in my mind. Locke himself recognizes this difficulty:

[...] "Knowledge placed in our ideas may be all unreal or chimerical". I doubt not but my reader, by this time, may be apt to think that I have been all this while only building a castle in the air; and be ready to say to me: "To what purpose all this stir?" Knowledge, say you, is only the perception of the agreement or disagreement of our own ideas: but who knows what those ideas may be? (Book IV, chap. IV, §1).

But immediately after making the problem explicit, he advances in his solution proposal:

Principia 21(3): 445-459 (2017). 
[Because the mind knows not things immediately, but only by the intervention of the ideas it has of them] Our knowledge, therefore is real only so far as there is a conformity between our ideas and the reality of things. (Book IV, chap. IV, §3).

Note that indirect realism posits the existence of a world that is independent of our experience and thus commits itself to a dualistic position: an ontology of nonphysical objects (the sense data, or ideas) together with an ontology of physical objects that are independent of our experience. How do these two object domains connect to each other? Locke himself gives us the answer:

For, the having the idea of anything in our mind, no more proves the existence of that thing, than the picture of a man evidences his being in the world, or the visions of a dream make thereby a true history [... ] It is therefore the actual receiving of ideas from without that gives us notice of the existence of other things, and makes us know, that something doth exist at that time without us, which causes that idea in us; though perhaps we neither know nor consider how it does it (Book IV, chap. XI, §§1-2).

In this way, although Locke's argument would not convince any skeptic, it lays the foundations of a causal theory of perception. I propose to apply a partially similar explanation to bridge the gap between models and the world, and challenge the Loss of Reality Objection. Just as sensations take us back to the existence of an independent reality, so the data models constructed from measurements and experimental results cannot but let us know, in a partial and approximate way, about certain objective aspects of the world. It is true that van Fraassen resists the idea that phenomena present themselves already "carved at their joints" regardless of how we represent them. The image of an isomorphic (or homomorphic) correspondence between the structure represented in data models and a supposed structure of the phenomena as they are in themselves is linked to metaphysical realism, which van Fraassen has been rejecting since The Scientific Image. And he emphasizes that "the measurement outcome shows not how the phenomena are but how they look" (van Fraassen 2008, p.290). He argues that a phenomenon can be measured and observed in different ways, from different perspectives, and according to different selections of certain aspects that depend on our objectives and interests. But, in our opinion, this does not mean that there are no facts of the matter restricting the varied possible ways of constructing the data models. Moreover, the coincidence between measurements and results of observations carried out in different situations and moments and through different experimental procedures seems to be sufficient basis to infer that the structure of the data model fits into the structure of the phenomena.

It could be argued, perhaps, that we have used a resource which is typically realist, a kind of argument to the best explanation, and that we do not take into consideration the criticisms that van Fraassen himself has formulated on this type of

Principia 21(3): 445-459 (2017). 
inference. We have two comments to make on this point. Firstly, although it is true that the inference to the best explanation has been the main argument held by realists in favor of their position, it does not seem that they have nor should have exclusive rights to use it. And secondly, regarding the fact that van Fraassen explicitly rejected such a resource, it should be noted that according to the voluntarist thesis defended by him, inference to the best explanation, as any other type of ampliative inference, although it lacks compelling force, is nonetheless permissible.

We are not proposing that we can know the structure of phenomena as it is in itself; we only affirm that we can, from measurements and experimental results (appearances), attribute a non-arbitrary structure in which the world plays, in fact, an important role.

It is a position like the one Putnam himself attributes to van Fraassen and declares to subscribe. In 1978, in the discussion following the work of van Fraassen included in the compilation edited by Massimo Piattelli Palmarini, Livelli di realtà, Putnam alludes to the type of evolutionism adopted by van Fraassen to account for the success of our current theories. This evolutionism takes distance from the "bad version" of evolutionism he attributes to Kuhn, and according to which we do not need to assume that there is a real world at all, because after all, the success of science can be explained only with evolution, without the intervention of any property of the environment (Putnam 1978). According to Putnam, any explanation of success must involve both the properties of the organism and the properties of the environment; and this is, in his opinion, the kind of evolutionism that van Fraassen has in mind.

Likewise, years later, van Fraassen himself declared his sympathy with the position that Putnam embraced in the 80s, internal realism. As in the case of Locke, being aware of the possibility of succumbing to relativism/skepticism, in Reason, Truth and History, Putnam pointed out that "internalism does not deny that there are experiential inputs to knowledge; knowledge is not a story with no constraints except internal coherence" (Putnam 1981, p.54). Naturally, if there are such inputs it seems necessary to postulate an external reality, a reality that - although unknowable and indescribable - is the substrate from which those inputs come. These ideas are obviously reminiscent of Kant's theory of knowledge, and Putnam recognizes that Kant was the first to propose the internalist perspective. ${ }^{4}$ Subsequently, in The Many Faces of Realism (1987), Putnam remembers what his goal was in Reason, Truth and History quoting his own words:

I shall advance a view in which the mind does not simply 'copy' a world which admits description by One True Theory. But my view is not a view in which the mind makes up the world (or makes it up subject to constraints imposed by 'methodological canons' and mind-independent 'sensedata'). If one must use metaphorical language, then let the metaphor be this: the mind and the world jointly make up the mind and the world (Putnam 1987, p.1).

Principia 21(3): 445-459 (2017). 
And in a footnote in the paper "Can Empiricism Leave Its Realism Behind?" (2009), van Fraassen refers to Putnam's book The Many Faces of Realism, and states:

Recall a famous saying by Hilary Putnam: "the mind and the world jointly make up the mind and the world" [...] (Hilary Putnam, Reason, Truth, and History, p.xi. Cited and discussed further in his 1987, Preface, p.1). In the first lecture in his 1987 he rejects subjective idealism; his aim is to show that common sense realism and conceptual relativism are compatible. I'd like to think that I'm showing something similar, although I would resist the name "conceptual relativism" as misleading, and also insist that any attempt to express the view in third person non-indexical language is self-defeating (van Fraassen 2009, p.470) [Our italics].

Van Fraassen's insistence on the indexical component is also reminiscent of Putnam's words when he says that what internalism denies is "that there are any inputs which are not themselves to some extent shaped by our concepts, by the vocabulary we use to report and describe them" (Putnam 1981, p.54). Van Fraassen finally recognized the importance of introducing the distinction between phenomena and appearances, a distinction which was absent in The Scientific Image, and, in this way, we believe, he put an interface (the data models) in our relationship with the world.

To summarize, the way in which theoretical models represent phenomena replicates certain features of Locke's indirect realism or of the more contemporary internal realism advocated by Putnam. Direct access is not possible, our only access is mediated, but that is not tantamount to the loss of the world. The only access to reality is, ultimately, through the representation of phenomena by means of their appearances. And this is all there is, an empiricism with a human face!

\section{Acknowledgments}

I would like to thank anonymous reviewers for their valuable suggestions for improving an earlier version of this paper.

\section{References}

Barrett, J. A. 2009. Bas C. van Fraassen. Scientific representation: Paradoxes of perspective. Journal of Philosophy 106(11): 634-639.

Duhem, P. M. M. 1906[1954]. The Aim and Structure of Physical Theory. Princeton: Princeton University Press.

French, S. 1999. Models and Mathematics in Physics. In: J. Butterfield; C. Pagonis (eds.) From Physics to Philosophy. Cambridge U.P.

Ghins, M. 2016. Bas van Fraassen on Success and Adequacy in Representing and Modelling. In: L. Magnani; C. Casadio (eds.) Model-Based Reasoning in Science and Technology, pp.2142. Switzerland: Springler.

Principia 21(3): 445-459 (2017). 
Giere, R. N. 2009. Essay Review: Scientific Representation and Empiricist Structuralism. Philosophy of Science 76: 101-111.

Ladyman, J. 1998. What is Structural Realism? Studies in History and Philosophy of Science 29: 409-424.

Locke, J. 1690 [1894]. An Essay Concerning Human Understanding. Edited by Alexander Campbell Fraser. 2 vols. Oxford: Clarendon Press.

Maxwell, G. 1970. Theories, Perception and Structural Realism. In: R. Colodny (ed.) The Nature and Function of Scientific Theories. University of Pittsburgh Press.

Nguyen, J. 2016. On the Pragmatic Equivalence between Representing Data and Phenomena. Philosophy of Science 83: 171-191.

Poincaré H. 1902[1968]. La science et l'hypothèse. Paris: Flammarion.

Putnam, H. 1981. Reason, Truth and History. Cambridge: Cambridge University Press.

- 1987. The Many Faces of Realism: The Paul Carus Lectures. LaSalle, Illinois: Open Court.

Rosenhagen, R. 2006. Indexical Truth and Antimetaphysical Inclinations. Getting Rid of the Remnants of Realism. In: A. Berg-Hildebrand; C. Suhm (eds.) Bas C. van Fraassen. The Fortunes of Empiricism, pp.81-92. Frankfurt: Ontos Verlag.

Russell, B. 1927. The Analysis of Matter. London: RKP.

van Fraassen, B. C. 1984. Sulla realta degli enti matematici. In: M. Piatelli-Palmerini (ed.) Livelli di Realta. Milano: Feltrinelli.

- 1980. The Scientific Image. Oxford: Oxford University Press.

- 2006. Structure: its Shadow and Substance. The British Journal for the Philosophy of Science 57(2): 275-307.

— 2008. Scientific Representation: Paradoxes of Perspective. Oxford: Oxford University Press.

- 2009. Can Empiricism Leave Its Realism Behind? Toward a Dialogue with Transcendentalists. In: M. Bitbol; P. Kerszberg; J. Petitot (eds.) Constituting Objectivity. Transcendental Perspectives on Modern Physics. Switzerland: Springer.

- 2012. The Criterion of Empirical Grounding in the Sciences. In: W. J. Gonzalez (ed.)

Bas van Fraassen's Approach to Representation and Models in Science, pp.79-100. Dordrecht, Heidelberg, New York, London: Springer.

Weyl, H. 1963. Philosophy of Mathematics and Natural Science. Atheneum.

Worrall, J. 1989. Structural Realism: The Best of Both Worlds? In: D. Papineau (ed.) The Philosophy of Science, pp.139-165. Oxford: Oxford University Press.

Zahar, E. 1996. Poincaré's Structural Realism and his Logic of Discovery. In: J.-L. Greffe; G. Heinzmann; K. Lorenz (eds.) Henri Poincaré: Science and Philosophy. Berlin: Academie Verlag and Paris: Albert Blanchard.

NÉLIDA GENTILE Universidad de Buenos Aires Facultad de Filosofía y Letras Puán 430. CABA (1406) nellygentile@gmail.com nelgen@filo.uba.ar 


\section{Notes}

${ }^{1}$ Although its first explicit formulation is due to Worrall (1989), there are important historical antecedents (Poincaré 1902, Duhem 1905, Russell 1927, and G. Maxwell 1970).

${ }^{2}$ van Fraassen states in a footnote that he has only very slowly recognized the importance of marking this distinction, which is absent in The Scientific Image (van Fraassen 2008, p.391 $\mathrm{n} 24$ ). We can add that although the interface of the appearances had already been incorporated in his 2006 paper, that was then done without adding any major specifications. It is also to be noted that here the meaning of the term "appearance" differs substantially from the one it assumes in Kant's doctrine, a point explicitly admitted by van Fraassen (see van Fraassen 2008, p.8).

${ }^{3}$ According to van Fraassen, expressions such as "theoretical entity" and "observabletheore-tical dichotomy" contain a category mistake. All language is theoretical; entities are observable or unobservable (van Fraassen 1980, p.14).

${ }^{4}$ Unlike Kant's, Putnam's conception does not include any reference to the noumenon. Moreover, according to Putnam, "Today the notion of a noumenal world is perceived to be an unnecessary metaphysical element in Kant's thought" (Putnam 1981, p.61). However, immediately after this statement, he adds: "But perhaps Kant is right: perhaps we can't help thinking that there is somehow a mind-independent 'ground' for our experience even if attempts to talk about it lead at once to non-sense" (Putnam 1981, pp.61-62).

${ }^{5}$ At this point, van Fraassen seems to have followed a path that is somewhat reversed with respect to that of Putnam, who finally abandoned the idea that there is an interface between our thinking and the world and went on to embrace direct realism or natural realism, to use his own words.

Principia 21(3): 445-459 (2017). 